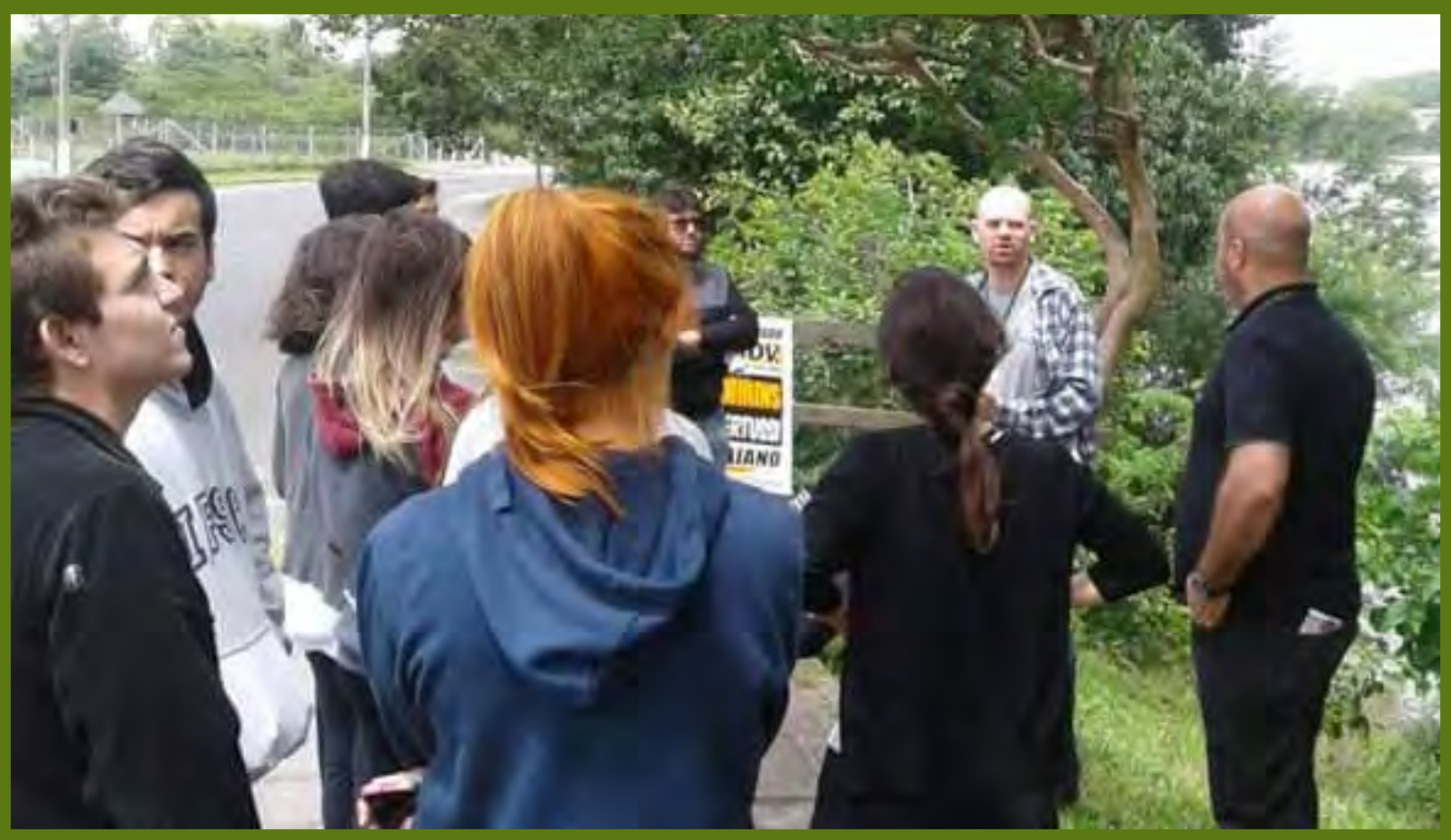

\title{
Caminhando por Araranguá: um roteiro histórico, cultural e ambiental
}

Rodrigo da Costa Lima'

rodrigo.lima@ifsc.edu.br

\section{Maurício Dalpiaz Melo²}

mauricio.dalpiaz@ifsc.edu.br

Anna Maria de Souza Córdova ${ }^{3}$

annascordova@gmail.com

André Vinicio Bialeski Vieira ${ }^{4}$

avbvieira125@gmail.com

1 Mestre em Sociologia (UFRGS). Docente de Sociologia IFSC/Campus Araranguá.

2 Mestre em Geografia (UFSC). Docente em Geografia IFSC/Campus Araranguá.

3 Graduanda do curso de História (UNESC).

4 Graduando do curso de História (UDESC). 
0 projeto "Caminhando por Araranguá: um roteiro histórico, cultural e ambiental" foi desenvolvido entre 2017 e 2018 no IFSC-Araranguá, entendendo a cidade como um território educativo (SINGER, 2015). Foi criado um roteiro educacional realizado a pé pelo centro histórico de Araranguá (SC), abordando aspectos patrimoniais e ambientais com enfoque interdisciplinar. 0 roteiro foi conduzido por alunos dos cursos técnicos integrados em eletromecânica e vestuário, com suporte de sinalização afixadas na Praça Hercílio Luz, cuja finalidade é indicar um website onde se encontra acessível o roteiro local.

Palavras-chave: Roteiro a pé. Território educativo. Cidade educadora. Cultura.

ABSTRACT

The project "Walking through Araranguá: a historical, cultural and environmental itinerary" was developed between 2017 and 2018 at IFSC-Araranguá, understanding the ity as an educational territory (SINGER, 2015). An educational itinerary was created to be done on foot in the historic center of Araranguá (SC), addressing heritage and environmental aspects with an interdisciplinary approach. The route was conducted by students from integrated technical courses in electromechanics and clothing production with an informative standing sign placed at Hercilio Luz square, whose purpose is to indicate a website where the local itinerary is accessible.

Keywords: Walking tour. Educational territory. Educating City. Culture.

\section{Relato de experiência}

0 projeto de extensão "Caminhando por Araranguá: um roteiro histórico, cultural e ambiental" foi desenvolvido no Campus Araranguá do Instituto Federal de Santa Catarina, entre os anos de 2017 e 2018. Durante o ano de 2018, foi contemplado pelo edital de financiamento interno para projetos de longa duração (Edital 2018, PROEX 01/APROEX 03). As parcerias com a Prefeitura Municipal de Araranguá, por meio do Departamento de Cultura, e com o Santuário Nossa Mãe dos Homens foram fundamentais para a sua execução.

0 projeto teve como objetivo analisar aspectos históricos, culturais e ambientais da cidade de Araranguá. Realizou-se a elaboração de um roteiro a pé, através de percursos significativos na cidade, como meio de ensino-aprendizagem, a partir de uma perspectiva interdisciplinar. Elaboraram-se também suportes de sinalização na Praça Hercílio Luz (Centro Histórico), que indica acesso ao website para a realização do roteiro autoguiado.

Figura 1: Início do roteiro (Praça Hercílio Luz)

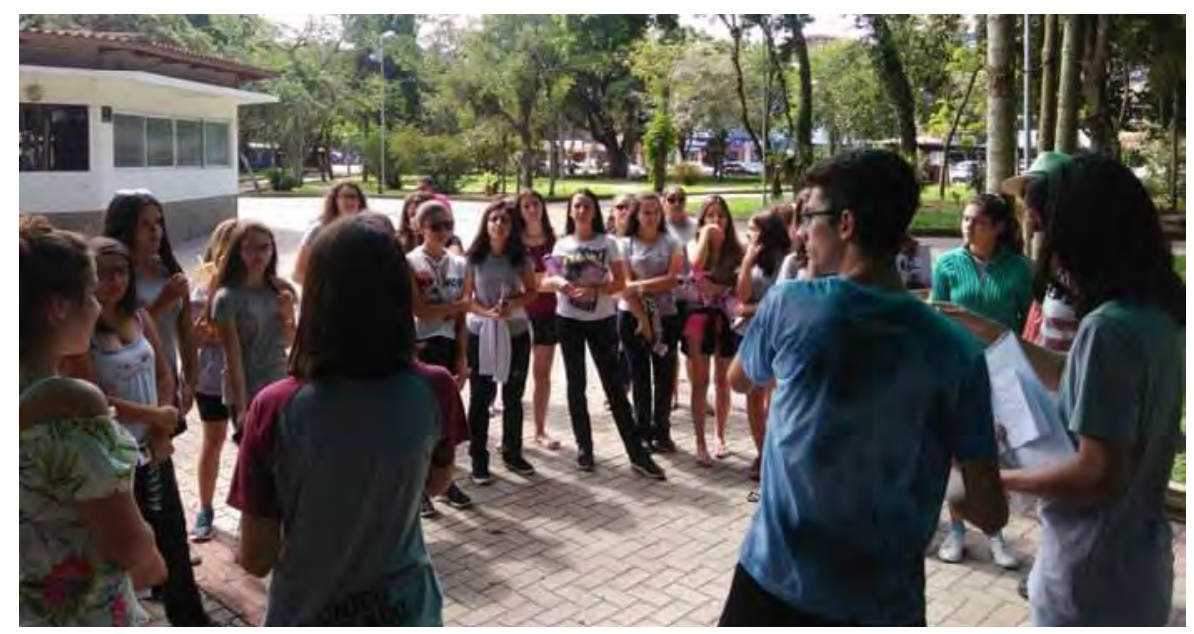

FONTE: Autores, 2018

Inspirado no movimento das Cidades Educadoras, iniciado em 1990, com o primeiro Congresso Internacional de Cidades Educadoras, realizado em Barcelona (Espanha), o projeto "Caminhando por Araranguá" partiu do princípio de compreender a cidade de Araranguá como um espaço educativo, superando os limites da sala de aula e considerando o espaço urbano como um ambiente de socialização, conflitos e comunicação. 
A cidade, em uma perspectiva educativa, pode ser considerada a partir de três dimensões distintas, mas complementares. Em primeiro lugar como entorno, contexto ou contida de instituições e acontecimentos educativos: 'educar-se ou aprender na cidade' seria o lema que descreve esta dimensão. Em segundo lugar, a cidade é também um agente, um veículo, um instrumento, um emissor de educação (aprender da cidade). E em terceiro lugar, a cidade constitui em si mesma um objeto de conhecimento, um objetivo ou conteúdo de aprendizagem: aprender a cidade. (BERNET apud SINGER, 2015, p. 16).

Portanto, buscou-se "[...] privilegiar uma visão cultural e relacional da cidade, organizada em função do contributo dos seus cidadãos, que devem ter o direito e o dever de participar activamente na construção de um espaço comum." (MARQUES; MOREIRA, 2009, p.1756).

Durante a execução do projeto, entre 2017 e 2018, foram realizados dez roteiros que contaram com a participação de 240 estudantes, de cinco escolas das redes públicas estadual, municipal e federal de Araranguá.

Figura 2: llustração do roteiro.

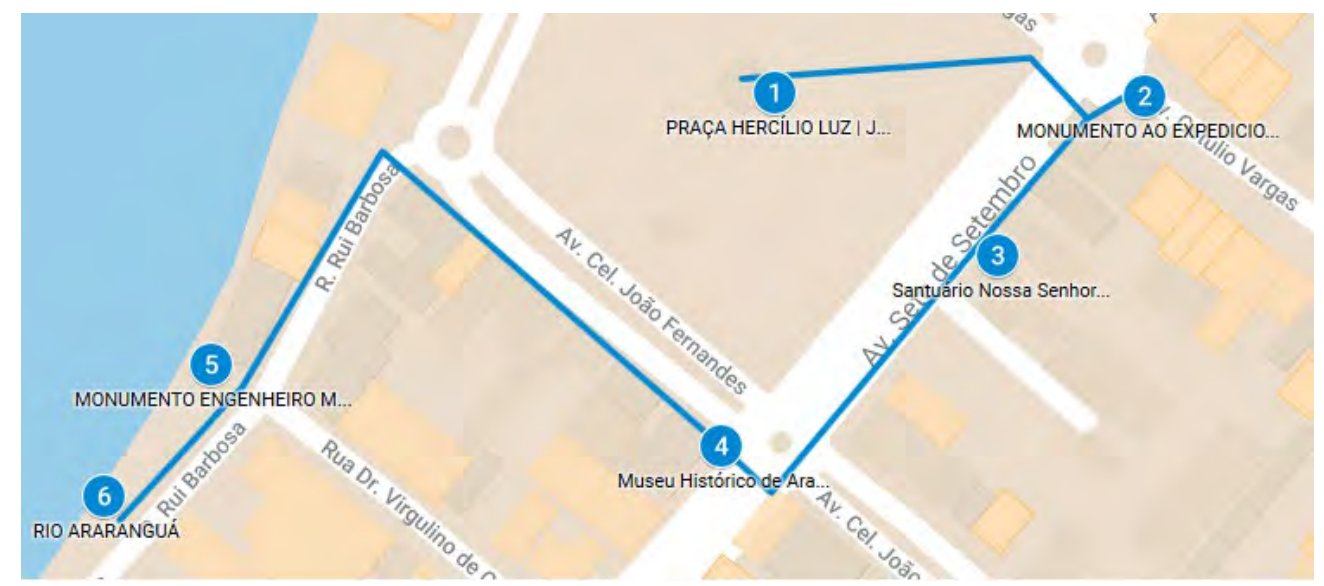

FONTE: Google Maps, 2018

No final do ano de 2018, como uma forma de permitir que o projeto tivesse maior alcance, foram entregues à cidade dois suportes de sinalização que apresentam o trajeto e disponibilizam um QR-Code que direciona para o website, no qual estão disponíveis informações sobre o caminho a ser percorrido por meio de textos e podcasts que abordam cada um dos seis pontos.

Figura 3: Placa instalada na Praça Hercílio Luz (Centro Histórico de Araranguá)

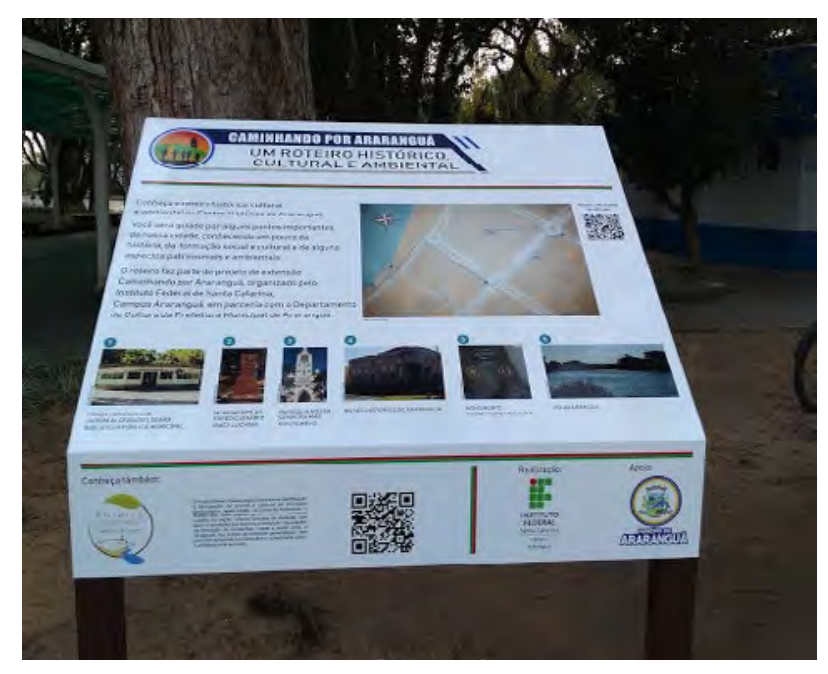


O roteiro inicia na praça Hercílio Luz/Jardim Alcebíades Seara, onde se aborda a origem de Araranguá, apresentando a história desde os primeiros habitantes da região até a fundação da cidade. Os Povos do Sambaquis, Xoklengs e Guaranis fizeram as primeiras ocupações na região, por volta de 6.000 a.C. Oficialmente, Araranguá surgiu a partir de 1728, com a rota dos tropeiros, na abertura do chamado Caminho dos Conventos. A presença dos novos moradores causou a ocupação destas terras ao sul de Laguna. 0 processo também foi intensificado pela chegada dos imigrantes italianos e açorianos. Araranguá emancipouse de Laguna em 1880 (HOBOLD, 2005).

Figura 4: Website desenvolvido pelo projeto

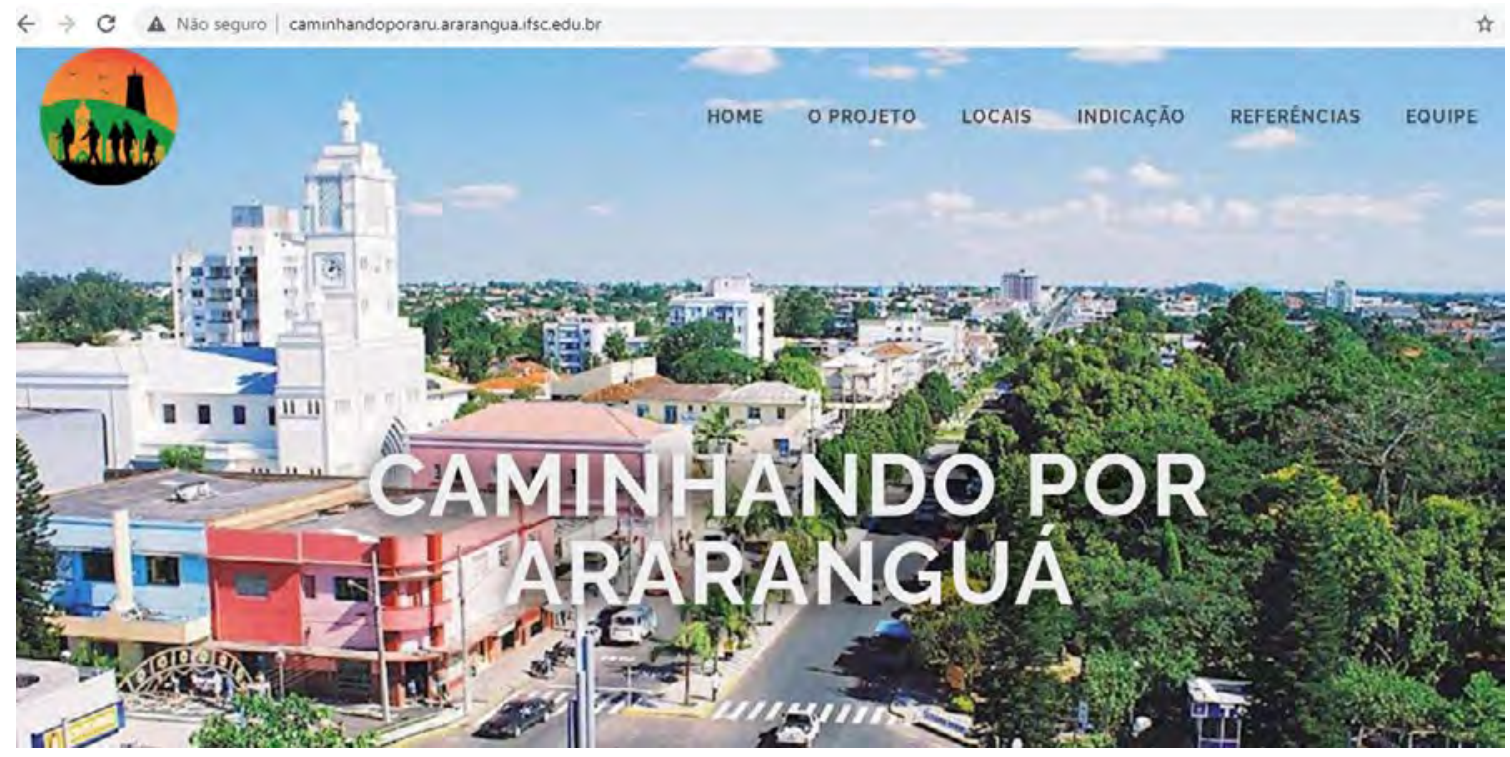

FONTE: Autores, 2018

Neste primeiro ponto, além da fundação da cidade, é exposta uma breve explicação sobre a história de Alcebíades Seara, ex-prefeito de Araranguá, salientando o monumento em sua homenagem, e do exgovernador de Santa Catarina Hercílio Luz, quem dá nome a praça. Adiante é realizada a visita à Biblioteca Municipal Luiz Delfino, sendo nomeada em homenagem a um grande escritor catarinense. Entre as décadas de 1940 e 1970 este lugar servia de coreto como palanque público e tem ainda em sua estrutura interna indicações daquele período.

0 segundo ponto a ser visitado é o Monumento Expedicionário Iracy Luchina, que homenageia um membro do 11ำ Regimento de Infantaria da Força Expedicionária Brasileira (FEB). Iracy Luchina foi morto em 12 de dezembro de 1944 na Itália, região de Monte Castelo. A batalha de sua morte foi conhecida com os '17 de Abetaia'. Em 1962 Araranguá recebeu o Diploma de Cooperador na Guerra, que foi entregue pela associação dos ex-combatentes do Brasil.

0 terceiro ponto é dedicado à exposição do Santuário Nossa Senhora Mãe dos Homens. Nele se conta a trajetória da igreja, iniciando pela criação em 1848 da Freguesia de Nossa Senhora Mãe dos Homens. Em 1864 foi construída sua primeira capela; a segunda, em 1902; e a terceira, em 1956 - atual sede matriz da cidade, elevada em 2018 a Santuário. A tradição católica é muito presente na cidade, a procissão com a imagem da padroeira ocorre todos os anos, no dia 4 de maio, sendo a data feriado municipal.

Logo adiante, no quarto ponto, encontra-se o Museu Histórico de Araranguá, também nomeado como Centro Cultural "Artesã Máxima Astrogilda de Souza", que abriga exposições itinerantes, Arquivo Histórico e sala de ensaios da banda municipal. Entre 1940 e 1996, o local serviu como agência bancária. Inaugurado em 1998, o Centro Cultural consolida a divulgação e preservação da literatura, do artesanato, da história e da música, além de outras manifestações artísticas da região.

Posteriormente, no quinto ponto, apresenta-se o Monumento Engenheiro Mesquita. Araranguá foi uma cidade com plano urbano, criada pelo Engenheiro Antônio Lopes de Mesquita, em 1886 (PIMENTA, 2000). A partir de então, a cidade passou a estruturar-se. Em 1967 um monumento em homenagem ao Engenheiro Mesquita foi construído pelo Lions Club, com objetivo de prestar agradecimento ao homem que deixou Araranguá conhecida como a "Cidade das Avenidas". 
Figura 5: Fim do Roteiro (Rio Araranguá)

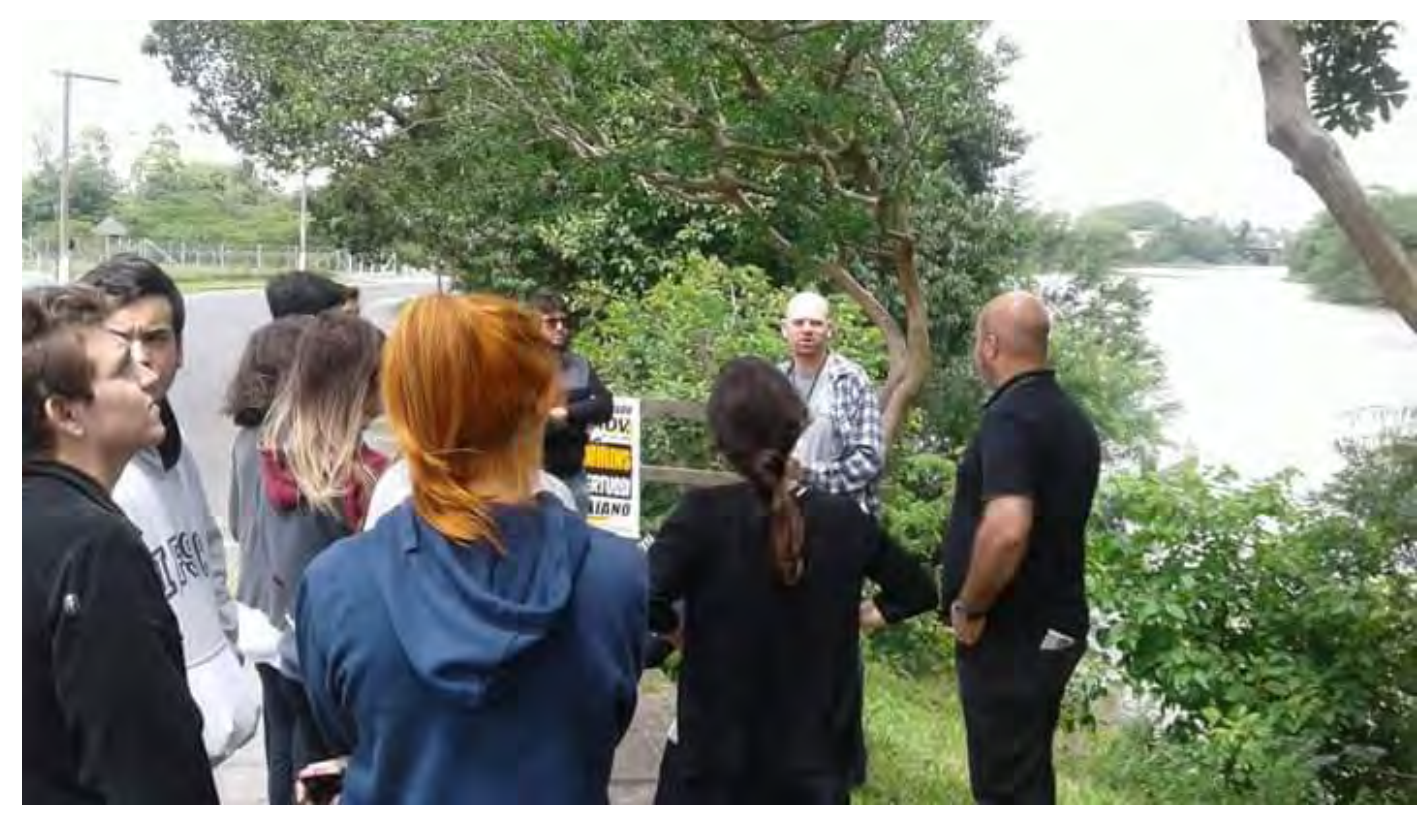

Fonte: Autores, 2017

Por último, no sexto ponto é apresentado o Rio Araranguá, que compõe a bacia hidrográfica de mesmo nome, sendo um dos principais sistemas de drenagem da região sul de Santa Catarina. 0 rio dá origem ao nome da cidade, e, entre as várias hipóteses a mais aceita é associada a existência de uma espécie de boto/ golfinho que emitia um som característico "iririm" que originou seu nome primitivo, "Iriringá", ou "Iriringuá", evoluindo até Araranguá. Atualmente o rio encontra-se em estado avançado de poluição. Nos seus afluentes, predomina o cultivo de arroz e a mineração do carvão e , com isso, a poluição se dá por agrotóxicos e resíduos da mineração. Este problema compromete os recursos hídricos, bem como provoca o assoreamento do leito do rio (SCHEIBE; BUSS; FURTADO, 2010).

Diante disso, o projeto "Caminhando por Araranguá", além de preservar a história e cultura local, também priorizou o incentivo à conservação ambiental da região, bem como a conscientização da importância do Rio Araranguá, uma grande riqueza natural existente.

\section{Referências}

Caminhando por Araranguá: um roteiro histórico, cultural e ambiental. Caminhando por Araranguá. Disponível em: <http://caminhandoporaru.ararangua.ifsc.edu.br/>. Acesso em 31 de agosto de 2020.

HOBOLD, Paulo. A história de Araranguá. Complementada e atualizada por Alexandre Rocha. Araranguá: Prefeitura Municipal de Araranguá, 2005.

MARQUES, Ana Paula; MOREIRA, Rita. Cidades educadoras: transferibilidade de boas práticas para os municípios do eixo atlântico. In: Braga: Atas do X Congresso Internacional Galego-Português de Psicopedagogia. 2009. p. 1754-1768. Disponível em: <http://www.redbcm.com.br/arquivos/CidadesCriativas/cidades\%20educadoras. pdf> Acesso em: 15 out. 2020.

PIMENTA, Margareth de Castro Afeche. Araranguá: expansão e plano. GEOSUL, Florianópolis, V. 15, № 29, P. 79-109, jan./jun. 2000.

SCHEIBE. Luiz Fernando.; BUSS. Maria Dolores.; FURTADO. Sandra Maria de Arruda. Atlas Ambiental da Bacia do Rio Araranguá/SC. Florianópolis: UFSC: Cidade Futura, 2010.

SINGER, Helena (Org.). Territórios educativos: experiências em diálogo com o Bairro-Escola. São Paulo: Moderna, 2015. 